\title{
Development, Fabrication, and Testing of a Liquid/Liquid Microchannel Heat Exchanger for Constellation Spacecrafts
}

\author{
Ebony Hawkins-Reynolds ${ }^{1}$ and Hung Le ${ }^{2}$ \\ GeoControl Systems Inc., Houston, TX 77087 \\ and \\ Ryan Stephan ${ }^{3}$ \\ Johnson Space Center, Houston, TX 77058
}

\begin{abstract}
Microchannel technology can be incorporated into heat exchanger designs to decrease the mass and volume of space hardware. The National Aeronautics and Space Administration at the Johnson Space Center (NASA JSC) partnered with Pacific Northwest National Laboratories (PNNL) to develop a liquid/liquid microchannel heat exchanger that has significant mass and volume savings without sacrificing thermal and pressure drop performance.
\end{abstract}

PNNL designed the microchannel heat exchanger to the same performance design requirements of a conventional plate and fin liquid/liquid heat exchanger; $3 \mathrm{~kW}$ duty with inlet temperatures of $26^{\circ} \mathrm{C}$ and $4^{\circ} \mathrm{C}$. Both heat exchangers were tested using the same test parameters on a test apparatus and performance data compared.

\section{Introduction}

In an effort to address the mass and volume concerns associated with spaceflight hardware, the Thermal Control System Development for Exploration project at Johnson Space Center partnered with Pacific Northwest National Laboratory (PNNL) to develop a microchannel liquid/liquid heat exchanger. PNNL expected that their technology would provide considerable mass and volume savings over state-of-the-art plate and fin heat exchangers.

PNNL designed and fabricated a microchannel liquid/liquid heat exchanger based on the performance criterion of a flight qualified plate and fin X-38 heat exchanger. The X-38 vehicle was designed to be used as an emergency crew return vehicle for the International Space Station. The microchannel heat exchanger was designed to transfer the same amount of heat as the X-38 heat exchanger and have equal or lower pressure drops for both the hot and cold fluid sides. To corroborate PNNL's claims of volume and mass savings, the X-38 heat exchanger was tested at the design point and its performance was used as a baseline to compare with the microchannel heat exchanger's performance.

\footnotetext{
${ }^{1}$ ESCG Project Engineer, Advanced Thermal Control Systems, Houston, TX 77058

${ }^{2}$ ESCG Project Manager, Advanced Thermal Control Systems, Houston, TX 77058

${ }^{3}$ JSC Project Manager, Advanced Thermal Control Systems, Houston, TX 77058
} 
The following test parameters were used to compare the X-38 and microchannel heat exchangers: heat transfer rate, pressure drops across the heat exchanger, overall heat transfer coefficient, heat exchanger effectiveness, mass, and volume.

\section{A. X-38 Heat Exchanger}

The X-38 heat exchanger is a stainless steel plate and fin counter-flow heat exchanger with core measurements of approximately 11.7 inches in length, 2.3 inches in height, and 1.8 inches in width (Figure 1). It has a mass of $2.7 \mathrm{~kg}$. It was designed to use deionized water and a 50:50 by mass ethylene glycol and water (EGW) mixture as the hot and cold working fluids, respectively. The X-38 heat exchanger design was optimized at the design point shown in Table 1.

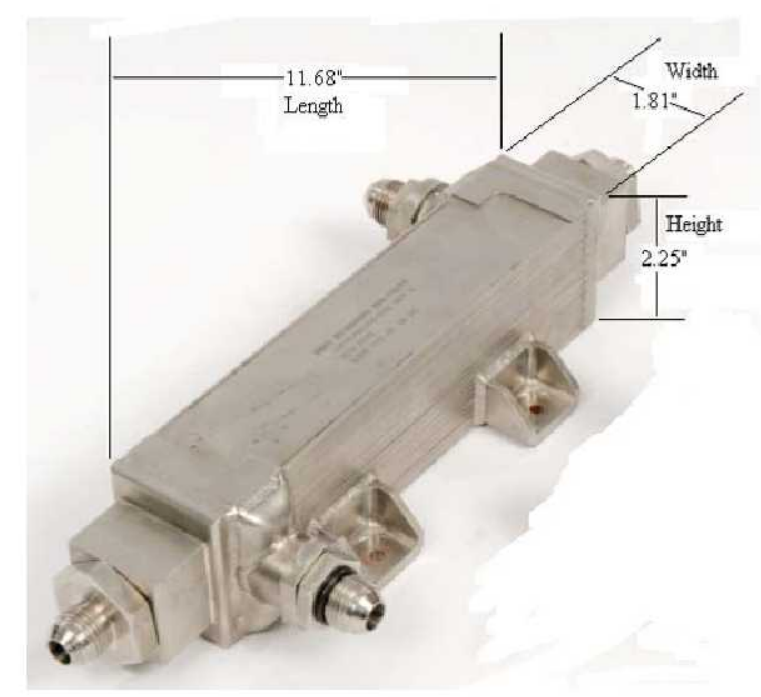

Figure 1. X-38 Heat Exchanger Core Dimensions

Table 1. X-38 Heat Exchanger Design Point

\begin{tabular}{|l|c|c|}
\hline Fluid: & DI Water & EGW \\
\hline Flow Rate $(\mathbf{l b m} / \mathbf{h r}):$ & 349 & 600 \\
\hline Inlet Temperature $\left({ }^{\circ} \mathbf{C}\right):$ & 26.6 & 4.4 \\
\hline Outlet Temperature $\left({ }^{\circ} \mathbf{C}\right):$ & 9.9 & 16.9 \\
\hline Maximum Pressure Drop (psid): & 0.5 & 0.5 \\
\hline Heat Transfer Rate $(\mathbf{k W}):$ & \multicolumn{2}{|c|}{3.1} \\
\hline
\end{tabular}




\section{B. Microchannel Heat Exchanger}

The microchannel heat exchanger was designed to meet or exceed the previously described $\mathrm{X}-38$ heat exchanger requirements. Pacific Northwest National Laboratory fabricated the microchannel heat exchanger using stainless steel. The microchannel heat exchanger core measures 1.9 inches in length, 3 inches in width and 3.3 inches in height as shown in Figure 2. The channels inside the microchannel heat exchanger measure approximately $0.1-0.3 \mathrm{~mm}$ creating more wetted surface area and thus resulting in a higher thermal conductance as the data will suggest.

Conventional plate and fin heat exchangers usually have low pressure drops because of the wider flow channels which allow the fluids to flow freely without added flow restrictions. The heat exchanger pressure drop is a strong function of the fluid selection

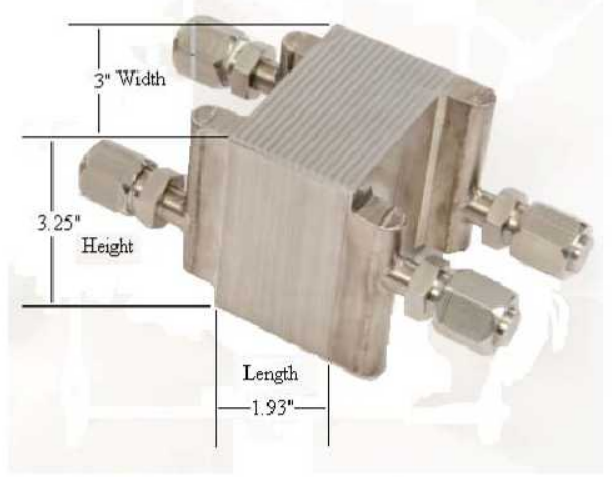

Figure 2. Dimensions of Microchannel Heat Exchanger Core. and the fluid viscosity (which is a function of the fluid temperature). Despite PNNL's claim to the contrary, the Thermal Control System Development for Exploration project was concerned that the microchannel heat exchanger would experience a higher pressure drop caused by the smaller flow channels.

Table 2 provides a comparison of the geometric specifications for the X-38 and microchannel heat exchangers. The mass and volume savings of the microchannel heat exchanger are evident. Figure 3 shows the two heat exchangers side by side. The difference in volume is noticeable.

Figure 3. Comparison of X-38 and Microchannel Heat Exchangers

Table 2. Heat Exchangers Geometric Specifications

\begin{tabular}{|c|c|c|}
\hline Heat Exchanger: & Mass & Core Volume \\
\hline X-38 & $2.7 \mathrm{~kg}$ & $48 \mathrm{in}^{3}$ \\
\hline Microchannel & $2 \mathrm{~kg}$ & $19 \mathrm{in}^{3}$ \\
\hline
\end{tabular}

\section{Test Setup}

The microchannel heat exchanger test loop was assembled on a 3' $\times 4^{\prime} \times 3^{\prime}(\mathrm{L} \times \mathrm{W} \times \mathrm{H})$ cart. All of the test loop components, excluding the chiller, were located on the cart. Figure 4 shows the mechanical schematic of the test loop for the heat exchanger test apparatus. The test loop was developed using two fluid loops. The main loop also called the hot loop used deionized water as the working fluid at a heat exchanger inlet temperature of approximately $27^{\circ} \mathrm{C}$. The 
chiller loop was nominally chilled to an inlet temperature of $4^{\circ} \mathrm{C}$ and used $50: 50$ by mass ethylene glycol and water mixture as the working fluid. The inlet temperatures were based on the design point for the $\mathrm{X}-38$ heat exchanger. The $\mathrm{X}-38$ and the microchannel heat exchangers were both individually tested in the test loop.

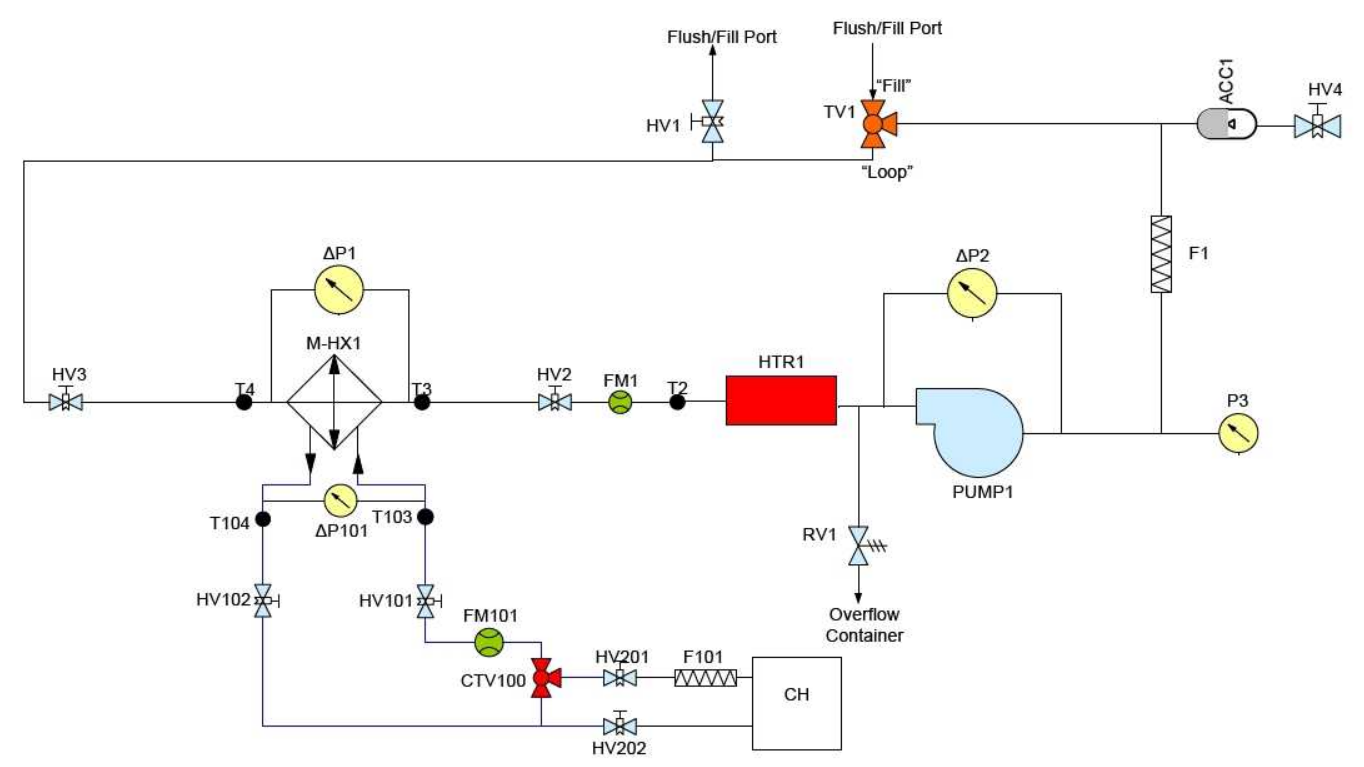

Figure 4. Microchannel Test Schematic

\section{Analysis}

The following equations ${ }^{4}$ were used to determine the heat exchanger performance.

Heat Transfer Rate:

$$
q=\dot{m} c_{p}\left(t_{2}-t_{1}\right)
$$

$m$ is the mass flow rate of the working fluid $(\mathrm{kg} / \mathrm{s})$,

$\mathrm{C}_{\mathrm{p}}$ is the specific heat of the fluid $\left(\mathrm{J} / \mathrm{kg}-{ }^{\circ} \mathrm{C}\right)$,

$\mathrm{t}_{2}$ is the inlet temperature $\left({ }^{\circ} \mathrm{C}\right)$, and

$t_{1}$ is the outlet temperature $\left({ }^{\circ} \mathrm{C}\right)$.

Heat Exchanger Effectiveness:

$$
\varepsilon=\frac{C_{h}\left(T_{h, i}-T_{h, o}\right)}{C_{\min }\left(T_{h . i}-T_{c, i}\right)}, \varepsilon=\frac{C_{c}\left(T_{c, o}-T_{c, i}\right)}{C_{\min }\left(T_{h . i}-T_{c, i}\right)}
$$

where, $C_{h}=c_{p, h} m_{h}$ and $C_{c}=c_{p, c} m_{c}$

\footnotetext{
${ }^{4}$ Incopera, Frank P., and David P. DeWitt. Fundamentals of Heat and Mass Transfer. Fourth Edition. New York. John Wiley \& Sons.
} 
$\mathrm{C}_{\mathrm{h}}$ and $\mathrm{C}_{\mathrm{c}}$ are the heat capacity rates of the hot and cold fluids, respectively $\left(\mathrm{W} /{ }^{\circ} \mathrm{C}\right)$,

T values are the inlet and outlet temperatures of the heat exchanger on the cold and hot sides $\left({ }^{\circ} \mathrm{C}\right)$, i.e. $T_{h, i}$ is the temperature for the hot side, ${ }_{\mathrm{h}}$, inlet, $\mathrm{i}$, and

$\mathrm{C}_{\min }$ is the minimum heat capacity rate of the two working fluids $\left(\mathrm{W} /{ }^{\circ} \mathrm{C}\right)$.

Overall Heat Transfer Coefficient:

$$
\begin{gathered}
U A=\frac{q}{\Delta T_{l m}} \\
\text { where, } \Delta T_{l m}=\frac{\left(T_{h, i}-T_{c, o}\right)-\left(T_{h, o}-T_{c, i}\right)}{\operatorname{Ln}\left(\frac{T_{h, i}-T_{c, o}}{T_{h, o}-T_{c, i}}\right)}
\end{gathered}
$$

$\mathrm{U}$ is the overall heat transfer coefficient $\left(\mathrm{W} / \mathrm{K}-\mathrm{m}^{2}\right)$,

A is the total surface area $\left(\mathrm{m}^{2}\right)$,

$\mathrm{q}$ is the heat transfer rate $(\mathrm{W})$, and

$\Delta T_{\text {Im }}$ is the log-mean temperature difference $(K)$.

The heat transfer equation was used to determine the amount of heat being transferred between the two working fluids. The closer the heat transfer rates of the hot and cold sides are to one another the lower the heat exchange with the ambient environment.

The effectiveness is defined as the ratio of the actual heat transfer to the maximum possible heat transfer of the heat exchanger.

The overall heat transfer coefficient combines the convective heat transfer coefficients for the fluids to the heat exchanger walls and the conductive heat transfer across the heat exchanger walls. Heat exchanger effectiveness and overall heat transfer coefficient are additional parameters that were calculated and used to compare the X-38 heat exchanger and the microchannel heat exchanger.

\section{Test Results}

The results discussed are taken from the primary test point: $350 \mathrm{lb} / \mathrm{hr}$ at an inlet temperature of $27^{\circ} \mathrm{C}$ on the main loop and $600 \mathrm{lb} / \mathrm{hr}$ at an inlet temperature of approximately $4^{\circ} \mathrm{C}$ on the cold loop. The X-38 and microchannel heat exchangers were designed to have a heat transfer rate of $3.1 \mathrm{~kW}$ and a maximum pressure drop of $0.5 \mathrm{psid}$ across both the hot and cold sides. Table 3 shows the baseline test data for the X-38 and microchannel heat exchangers. 


\section{Table 3. X-38 and Microchannel Heat Exchangers Main Test Point and Design Point Values}

\begin{tabular}{|c|c|c|c|c|c|c|}
\cline { 2 - 7 } \multicolumn{1}{c|}{} & $\begin{array}{c}\mathbf{q}_{\text {hot }} \\
\text { (W) }\end{array}$ & $\begin{array}{c}\mathbf{q}_{\text {cold }} \\
\text { (W) }\end{array}$ & $\varepsilon$ & $\begin{array}{c}\text { UA } \\
\text { (W/k) }\end{array}$ & $\begin{array}{c}\Delta \mathbf{P}_{\text {hot }} \\
\text { (psid) }\end{array}$ & $\begin{array}{c}\Delta \mathbf{P}_{\text {cold }} \\
\text { (psid) }\end{array}$ \\
\hline X-38 & $2423 \pm 42$ & $2662 \pm 40$ & $.65 \pm .01$ & $261 \pm 10$ & $0.35 \pm .005$ & $0.54 \pm .012$ \\
\hline Microchannel & $3138 \pm 51$ & $3317 \pm 44$ & $.84 \pm .01$ & $553 \pm 10$ & $0.48 \pm .029$ & $0.95 \pm .028$ \\
\hline Design Point & \multicolumn{2}{|c|}{$3100 \mathrm{~W}$} & .75 & 415 & 0.5 & 0.5 \\
\hline
\end{tabular}

The X-38 heat exchanger failed to produce a heat transfer rate of $3.1 \mathrm{KW}$, while the microchannel produced a higher heat transfer rate for the prescribed inlet conditions. The X-38 heat exchanger's failure to produce the designed heat transfer rate can possibly be attributed to the cleanliness of the heat exchanger or possible fouling within the heat exchanger. However, the project has every reason to believe that the X-38 heat exchanger did indeed meet its performance requirements when it was delivered to NASA. As mentioned above, the X-38 heat exchanger was fabricated and was intended to serve as flight hardware. NASA would not have taken delivery of the hardware if it was not shown to meets its performance requirement. The X-38 heat exchanger did meet the pressure drop requirement of less than 0.5 psid on both sides of the heat exchanger. In fact, the X-38 heat exchanger had a pressure drop of 0.35 psid across the hot side and 0.54 psid across the cold side. The microchannel heat exchanger met the pressure drop requirement across the hot side with a pressure drop of $0.48 \mathrm{psid}$, but failed across the cold side at 0.95 psid. This data was shared with PNNL who used the test data to correlate their design model. PNNL has subsequently claimed that they could deliver another heat exchanger that would meet the pressure drop requirements while sacrificing on heat transfer performance, which would be acceptable because their heat exchanger performance exceeded the design requirement. To be exact, PNNL claims that they can deliver a new heat exchanger that meets all of the design requirements and has a mass of only $1.2 \mathrm{~kg}$ and a core volume of $188 \mathrm{~cm}^{3}$.

To determine how efficient the heat exchangers were, the effectiveness and the overall heat transfer coefficient were calculated. The microchannel heat exchanger had a higher effectiveness and heat transfer coefficient than the X-38 heat exchanger. The effectiveness is a measure that determines how well the heat exchanger is able to transfer heat from one fluid to the other. As shown in Table 3, the microchannel heat exchanger's effectiveness was .84 compared to .65 for the X-38 heat exchanger. This increase in effectiveness was due to the microchannel heat exchanger having larger temperature differences between the inlet and outlet temperatures than the X-38 heat exchanger. The microchannel heat exchanger overall heat transfer coefficient was $553 \mathrm{~W} / \mathrm{K}$, which was more than double the overall heat transfer coefficient of the X-38 heat exchanger. The X-38 heat exchanger heat transfer coefficient was calculated to be $261 \mathrm{~W} / \mathrm{K}$. The difference in overall heat transfer coefficient is due to either a higher thermal resistance between the working fluids in the X-38 heat exchanger or a much higher surface area in the microchannel heat exchanger or a combination of both. 


\section{Conclusion}

A plate and fin liquid/liquid X-38 heat exchanger was originally designed to have a heat transfer rate of $3.1 \mathrm{~kW}$ and pressure drops not to exceed 0.5 psid across both the hot and cold sides of the heat exchanger. The performance specifications from this heat exchanger were used to design a microchannel liquid/liquid heat exchanger. A test apparatus was designed and used to test both heat exchangers. The microchannel heat exchanger met all of its performance requirements with the exception of the pressure drop across the cold side of the heat exchanger. The microchannel heat exchanger's heat transfer rate, effectiveness and UA were higher although it weighs less and is smaller than the X-38 heat exchanger. The microchannel heat exchanger design achieved a mass reduction of $26 \%$. In addition, the microchannel heat exchanger core was reduced by $61 \%$ as compared to the X-38 heat exchanger.

The test data has been shared with PNNL. The project was especially concerned about PNNL's failure to meet the pressure drop requirements. To that end, PNNL has used the test data to develop correlated thermal models. These models were then used to conceptually design a next generation microchannel heat exchanger. The conceptual design shows improved mass and volume as compared to the first generation microchannel heat exchanger. This was achieved while sacrificing the thermal performance of the unit. This sacrifice was acceptable because the first unit exceeded the thermal performance specifications. The mass and core volume for the conceptual design is $1.2 \mathrm{~kg}$ and $188 \mathrm{~cm}^{3}$, respectively.

The project is in the process of developing a life test for the microchannel heat exchanger. This test is scheduled to run the baseline test point continuously for at least six months. The life test will provide insight into the performance of a microchannel heat exchanger over a long test duration. The project is concerned that the microchannel heat exchanger may be susceptible to performance degradation because of the extremely small flow passages. 